INTERNATIONAL JOURNAL OF RESEARCHES IN BIOSCIENCES, AGRICULTURE AND TECHNOLOGY

(C) VISHWASHANTI MULTIPURPOSE SOCIETY (Global Peace Multipurpose Society) R. No. MH-659/13(N) www.vmsindia.org

\title{
OPTICAL AND NLO BEHAVIOR OF L-LEUCINE DOPED ADP CRYSTAL
}

\author{
B. A. Shingade ${ }^{1}$, P. S. Sawadh ${ }^{2}$, N. S. Meshram ${ }^{3}$, \\ R. M. Belekar ${ }^{4}$ and K. G. Rewatkar ${ }^{5}$ \\ 1,2Bhawabhuti Mahavidyalaya, Amgaon,Gondia,MH- India.-441902 \\ ${ }^{3}$ Bapurao Deshmukh College of Engineering Sevagram, Wardha MH- India.-442102 \\ ${ }^{4}$ Dr. Ambedkar College,Deekshabhoomi, Nagpur,MH, India.-440010 \\ 5Arvindbabu Deskmukh Mahavidyalaya, Bharsingi, Nagpur,MH, India.-441305 \\ bashingade@gmail.com
}

\begin{abstract}
Pure ammonium dihydrogen phosphate (ADP) with L-Leucine doped has been grown by slow solvent evaporation method at room temperature. The grown crystals were characterized by X-ray diffraction, FTIR . The X-ray diffraction analysis of the grown ADP crystals showed that it possess tetragonal structure having lattice parameters $\mathrm{a}=7.626 \AA$ and $\mathrm{c}=7.715 \AA$. FTIR spectral analysis was performed to identify various functional groups in the crystal.
\end{abstract}

Key words: ADP, L-Leucine, X-ray diffraction, FTIR, etc.

\section{Introduction:}

Ammonium Dihydrogen Phosphate (ADP) is a representative of hydrogen bonded materials that possesses excellent dielectric, piezoelectric, anti-ferroelectric, electro-optic and nonlinear optical properties. Growth and studies of ammonium dihydrogen phosphate is a centre of attention to researchers because of its unique properties and wide applications. Single crystals of ADP are used for frequency doubling and frequency tripling of laser systems, optical switches in inertial confinement fusion and acoustic-optical Devices [1]. ADP crystallizes in a body centered tetragonal structure with the space group I $42 \mathrm{~d}$ and has tetra molecular unit cell [2] with unit cell parameters $\mathrm{a}=\mathrm{b}=7.6264$ $\AA$ and $\mathrm{c}=7.7151 \AA$. ADP has been the subject of a wide variety of investigations over the past decades. Reasonable studies have been done on the growth and properties of pure ADP [3-4]. In recent years, efforts have been taken to improve the quality, growth rate and properties of ADP, by employing new growth techniques, and also by the addition of organic, inorganic and semi organic impurities [5, 6]. Organic nonlinear optical materials have large optical susceptibilities, inherent ultrafast response times, and high optical thresholds for laser power as compared with inorganic materials. Amino acids are interesting materials for NLO applications as they contain a proton donor carboxyl acid $(-\mathrm{COOH})$ group and proton acceptor amino (-NH2) group in them [7]. Amino acids, when added as impurities, have improved material properties [8]. Amino acid, L-leucine has formed several complexes, which are promising materials for second harmonic generation $[9,10]$. In the light of research work being done on ADP crystals, to improve the properties, it was thought interesting and worthwhile to investigate the effect of L-leucine on ADP. In this work, the structural spectral and nonlinear optical behaviour of single crystals of L-leucine added ADP against pure ADP has been studied and reported.

\section{Experiment}

Ammonium dihydrogen phosphate and L-leucine (Merck-Germany) along with deionised water were used for the growth of single crystals. ADP was mixed with L-leucine in the ratio 1:0.04 to prepare $300 \mathrm{ml}$ of saturated solution at $35^{\circ} \mathrm{C}$ The solution was stirred for four hours using magnetic stirrer and filtered using Whatman filter paper. The filtered solution was transferred to borosil glass beaker. It was porously sealed and placed in a dust free atmosphere for slow evaporate n. $100 \mathrm{ml}$ of saturated solution of pure ADP was also prepared with de-ionised water at $30^{\circ} \mathrm{C}$.

The solution was stirred for four hours using magnetic stirrer. It was then filtered using Whatmann filter paper, transferred to borosil glass beaker, porously sealed and kept in a dust free atmosphere for slow evaporation. The grown Pure and 0.4 mol\% L-leucine added ADP crystals were harvested after a period of 30 days.

Crystals growth and characterization of ADP and doped ADP crystals were grown from an aqueous solution by slow evaporation and slow cooling techniques. Good quality crystals of reasonable size $(40 \mathrm{~mm} \mathrm{X8} \mathrm{mmX} 7 \mathrm{~mm}$ ) are obtained for a particular concentration shown in Figure. 1 and 2.

\section{Result and Discussion:}

Powder X-Ray diffraction (PXRD) Analysis: Powder of grown pure ADP and L-Leucine doped 
crystals were analyzed by XRD studies. The powder sample were loaded into X-Ray diffractometer with radiation $(\lambda=1.5406 \AA)$ with an operating voltage $40 \mathrm{kV}$ and current $35 \mathrm{~mA}$. Scanning rate was maintained at $32.8 \mathrm{~s}$ over a $2 \theta$ range of $10-800$. From this measurement we found the lattice parameters as $\mathrm{a}=\mathrm{b}=7.510 \AA$ and $\mathrm{c}=7.654 \AA$ for pure $\mathrm{ADP}$ and lattice parameter of L-Leucine doped crystals are well matched with the result reported[12], having symmetry space group I42d and result shows that L-Leucine entered into ADP lattice. No additional peaks are present in the XRD spectra of doped ADP crystal, showing the absence of any additional phases besides the tetragonal system, due to doping. The observed prominent peaks of all L- Leucine doped crystals are (101), (200), (112), (202), (301), (213), (114), (204), (323), are shown in Figure.. (2).The variation in intensity of diffracted peaks is found. The differences in the peak amplitude can be ascribed to the different sizes and orientation of the powered grains. The degree of sharpness of peaks indicates the crystallinity of the grown crystals. There is small variation in lattice parameters with concentration.
Fourier Transforms Infrared (FT-IR) analysis:

The powdered samples of L-Leucine doped ADP were also attempted to Fourier Transform Infrared (FT-IR) investigation. The spectrum was observed from VARIAN resolution pro FTIR spectrometer in the range 400- 4000 $\mathrm{cm}^{-1}$ by KBR pallet technique. The prominent peaks in the FT-IR pattern for different concentration of L-Leucine doped ADP crystals are shown in the Figure.. 5.The FT-IR spectra of pure ADP and L-Leucine doped ADP shows that band in the high energy region is due to free O$\mathrm{H}$ stretching of water, $\mathrm{P}-\mathrm{O}-\mathrm{H}$ group of pure and L-Leucine doped ADP[13]. Graphs of pure ADP and L-Leucine doped ADP have high similarities which indicate pure ADP peaks are predominant over L-Leucine peaks due to very small doping of L-Leucine From FT-IR spectrum of pure and LLeucine doped ADP it is been observed that all major peaks have shifted towards the higher wave number region, which indicates that dopant L-Leucine has brought about this changes.

The characteristics absorption frequencies of various functional groups are given in the following table

Table No - 1- Bond assignments of various frequency

\begin{tabular}{|l|l|l|l|}
\hline Sr.no & Frequency Range & \multicolumn{1}{|c|}{$\mathbf{0 . 4}$ mole\%+ADP } & Bond Assignments \\
\hline 1 & $3700-3100$ & 3255.88 & O-H Stretching \\
\hline 2 & $2800-2400$ & 2371.00 & Vibration of combination bond \\
\hline 3 & $1450-1200$ & 1445.65 & Bending vibration of NH2 \\
\hline 4 & $1100-900$ & 1099.10 & $\mathrm{P}^{-O}-\mathrm{H}$ vibration \\
\hline 5 & $550-430$ & 548.46 & $\mathrm{PO}_{4}$ Vibration \\
\hline
\end{tabular}

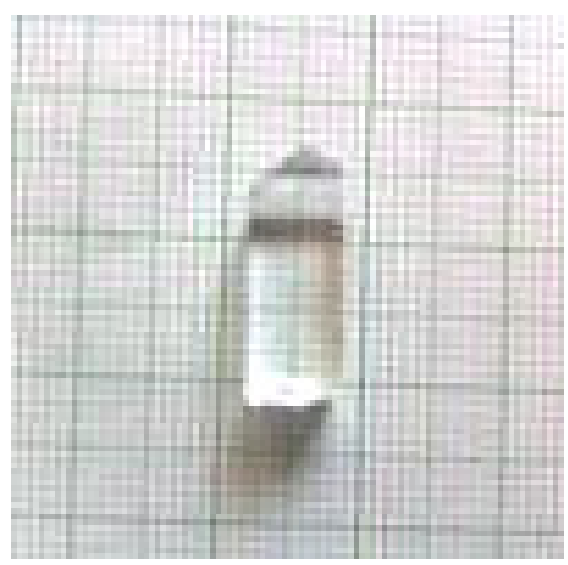

Figure. 1.pure ADP

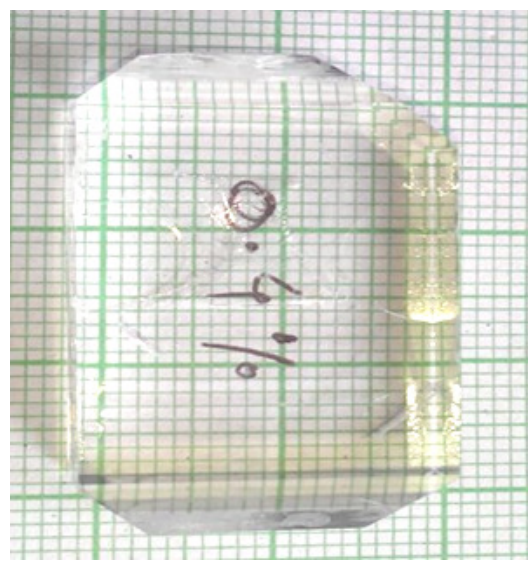

Figure. 2. $0.4 \%$ 


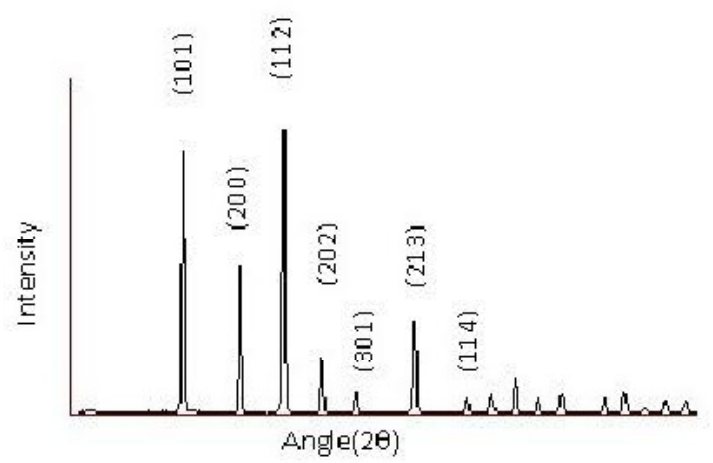

Figure. 3 PXRD of pure ADP

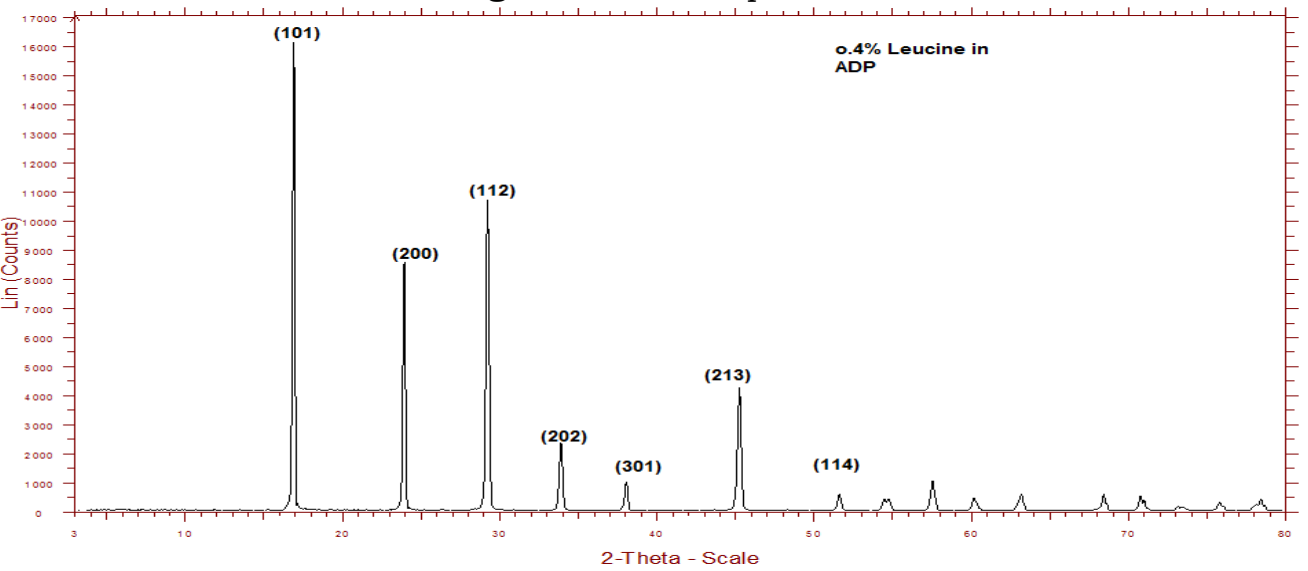

Figure. 4 PXRD of $0.4 \%$ Leucine doped in ADP

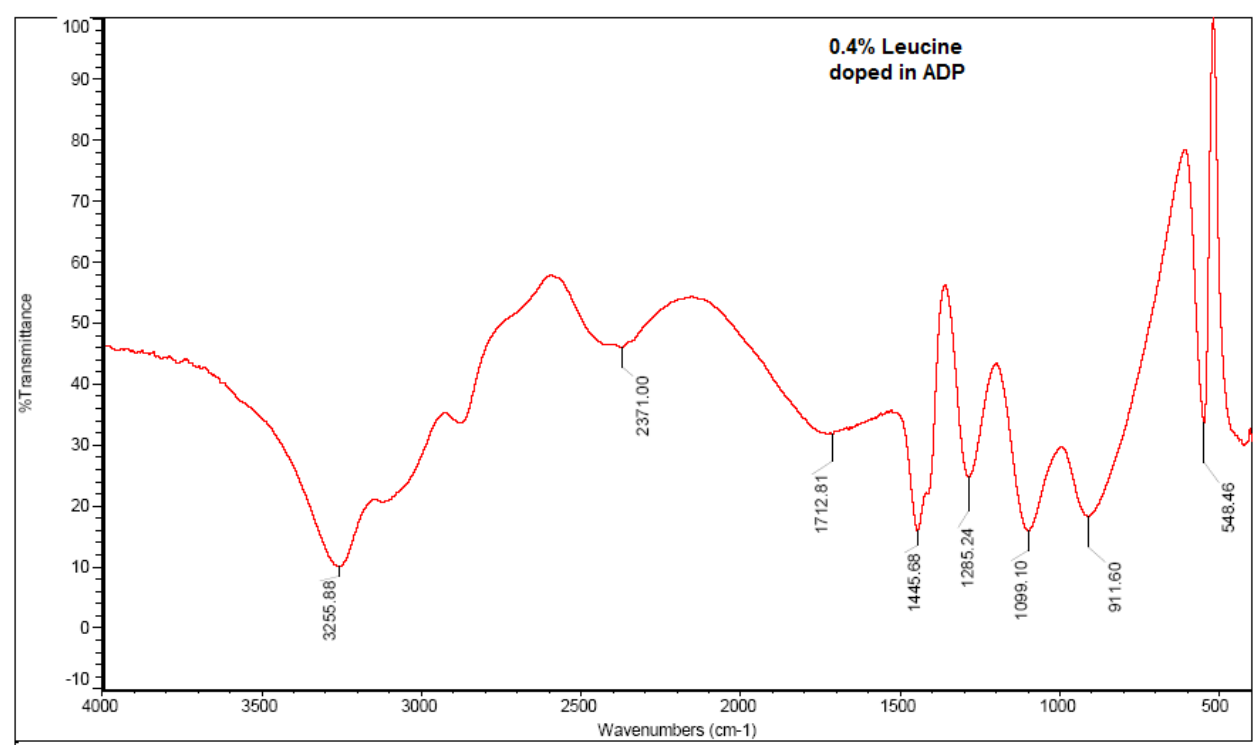

Figure. 5 FTIR of $0.4 \%$ Leucine doped ADP

\section{Conclusion:}

Optical quality, colorless and pure and 0.4 mole\%, L- Leucine doped ADP crystals were grown by slow evaporation technique at room temperature. The powder X-ray diffraction studies of pure and L-Leucine doped ADP showed that crystal posses tetragonal structure having I42d symmetry space group, with lattice parameter in good agreement with JCPDS data card no. 850815. Even after doping crystal system remains unchanged. Intensity peaks of L- Leucine doped ADP crystal resembles with diffraction angle of pure ADP crystal with negligible small variation, while intensity variation observed. The FT-IR spectrum confirms the presence of all functional group of L-Leucine.

\section{Acknowledgement:}

Author would like to thank the Principal, 
Bhawabhuti Mahavidyalaya Amgaon . Also express our gratitude towards Dr. P .S. Sawadh , Dr. K. G. Rewatkar and UGC for funding and providing necessary support and help.

\section{References}

1. N. Zaitseva, L. Carman, Prog. Crystal Growth Charact. 43 (2001) 1.

2. L. Tenzer, B.C. Frazer, R. Pepinsky, Acta Cryst. 11 (1958) 505.

3. H.v. Alexandru, J. Cryst. Growth 10 (1971) 151.

4. W.J.P. Van Enckevort, R. Janssen-van Rosmalen, W.H. Van der Linden, J. Cryst. Growth 49 (1980) 502.

5. P. Rajesh, P. Ramasamy, Materials Letters 63 (2009) 2260.

6. P.Selvarajan, J.Glorium Arul Raj, S.Perumal, J. Crystal Growth 311 (2009) 3835.
7. P. Kumaresan, S. Moorthy Babu, P.M. Anbarasan, Optical Materials 30 (2008) 1361.

8. P. Rajesh, P. Ramasamy, Physica B 404 (2009) 1611.

9. S.A. Martin Britto Dhas, G. Bhagavannarayana, S. Natarajan, J. Cryst. Growth 310 (2008) 3535.

10. G. Anantha Babu, P. Ramasamy, Mater. Chem. Phys. 113 (2009) 727.

11. H. Lipson, H. Steeple, Interpretation of X-ray Powder Diffraction Patterns, fifth edi. Macmillan, New York, 1970.

12. Dongli Xu, Dongfeng Xue, J. Cryst. Growth 286 (2006) 108

13. Josephine Rani T., et al. RRST 69(2011). 